\title{
CALORIMETRIC STUDIES OF THE EXTREMITIES
}

\author{
I. Theory and Practice of Methods Applicable to Such \\ INVESTIGATIONS \\ BY CHARLES SHEARD \\ (Section on Physics, Mayo Clinic and The Mayo Foundation, Rochester, Minnesota)
}

(Received for publication July 1, 1926)

\section{INTRODUCTION}

In 1912 Stewart delivered the Harvey lecture (9) on "Studies on the circulation in man," dealing almost entirely with blood flow in the hands and feet of both normal and abnormal persons. This lecture was preceded by two papers (8) concerning the measurement of blood flow in the hand and the effects of reflex vasomotor excitation. Since then, so far as I know, no additional experimental work on this subject has appeared in print other than the papers by Taylor.

In all of his writing Stewart adheres to the statement, "the quantity of blood in grammes flowing through the hand in the time of the experiment is given by the equation.

$$
Q=\frac{H}{T-T_{1}} \cdot \frac{1}{S}
$$

where $Q$ is the quantity of blood, $H$ the heat given off by the blood, $T$ the temperature of the arterial blood, $T_{1}$ the temperature of the venous blood and $S$ the specific heat of the blood" (9). I have not been able to accept the Stewart equation for the determination of blood flow, neither do I feel that such an equation can be correctly applied to the determination of " $Q$, the quantity of blood flowing through the hand (or foot) in the period of observation" (8). ${ }^{1}$ The heat taken up by the calorimeter obviously must

${ }^{1}$ A preliminary report and summary of the principal conclusions in this investigation were printed in Science, vol. lxiv, pages 21-22, July 2, 1926. Further comments made by Dr. Stewart are to be found in Science, pages 224-225, September 3, 1926. 
be delivered to it by the immersed extremity and, if there are no losses in the calorimeter, the heat $\left(H_{e}\right)$ given out by the extremity must equal the heat $\left(H_{c}\right)$ gained by the calorimeter and its contents. The fact that any given extremity has in its tissues a certain amount of heat or is at any determined temperature is evidence that there is or has been some flow of blood in that extremity, but it is not patent that calorimetric measurements afford a means of determining the quantity or rate of flow of blood.

When a temperature gradient exists between the extremity and the bath into which it is immersed, there will be a flow or delivery of heat from the extremity to the water. This flow of heat must take place through the skin which has a conductivity $K$ and a thickness $D$. Both of these factors no doubt vary considerably in different persons and practically nothing is known concerning either of them. Furthermore, the elimination of heat from the extremity is dependent not only on the rate or quantity of blood flow, but also on various conditions of the blood vessels and radiation factors, namely: $(a)$ dilated or constricted capillaries ${ }^{2}$ or surface blood vessels, in which event the area of blood surface taking part in the transfer of heat will be increased or decreased and hence permit a greater or less transfer of heat, $(b)$ the number of capillaries functioning, which is found to vary greatly in different individuals as has been demonstrated by microscopic studies of the capillaries of the skin $(1,2,4$, $6,7)$, and $(c)$ the capillary blood flow, dependent per se on the rate of blood flow in the capillaries and whether they are partially or wholly filled with blood at all times. In other words, the elimination of heat, as dependent on the blood per se, is conditioned by the total area of blood exposed in the surface capillaries and peripheral blood vessels, the number of capillaries functioning and the rate and quantity of blood flow in the capillaries. The transfer or conduction of heat from an extremity to the bath is dependent on the temperature gradient between the peripheral or surface circulation of blood and and the immersion bath, this being determined by the conductivity and the thickness of the skin.

\footnotetext{
${ }^{2}$ When capillaries are spoken of, reference is made to surface blood vessels, the major portion of which are undoubtedly the capillaries.
} 
THE EQUATION OF HEAT CONDUCTION AND THE RATE OF TRANSFER OF HEAT

In view of the foregoing remarks, the experiments of Brown, as well as those of Stewart, have to do primarily with the transfer or conduction of heat from one body to another and not with blood flow per se, these bodies being separated by an interface having a certain conductivity constant and temperature gradient. It seems logical to apply to these studies such mathematical equations as pertain to conduction of heat, and from the experimental data to draw conclusions relative to $(a)$ the inherent heat capacity ${ }^{3}$ or content of heat of the superficial tissues of an extremity, and $(b)$ the rate of transfer or elimination of heat from the blood as dependent on its surface distribution and flow under the physical conditions of temperature of the bath, and so forth, set up in these experiments.

The well known equation for heat conduction (11), which may be referred to as the quantity of heat eliminated by an extremity placed in a bath of known temperature, is

$$
Q=K\left(T_{1}-T_{2}\right) \frac{A}{D} t
$$

in which $Q$ is the quantity of heat in calories conducted from the extremity to the water, that is, eliminated from the foot, in a given time $t ; K$ is the conductivity constant, $T_{1}$ and $T_{2}$ are the temperatures respectively of the two bodies, one being at a higher temperature than the other; $A$ is the area over which the conduction of heat from one medium to another takes place; $D$ is the thickness and vascularity of the conducting layer, and $t$ is the time of conduction of heat. Very approximately, then, the transfer of heat from an extremity placed in a calorimeter may be considered as shown in figure $1 a$ in which $T_{1}$ represents the temperature of a liquid at a higher temperature than that of the bath at temperature $T_{2}$. The area $A$, thickness $D$ and the thermal conductivity $K$ are quantities which must be known in addition to the values of $T_{1}$ and $T_{2}$ if the quantity of heat conducted in a given time $t$ is to be calculated. In our present discussion,

${ }^{3}$ The inherent heat or thermal capacity of the foot represents the heat existing in the tissues with arterial flow checked. 
however, it is to be remembered that conditions are somewhat different from those in the simple system shown in figure $1 a$ because there is a circulatory system which, from the physical standpoint, may be considered as consisting of two portions, a central one and a peripheral one (fig. 1, $b$ and $c$ ). This is not strictly true from the anatomic standpoint, but it is felt that this classification into superficial and deep circulatory portions is permissible. The peripheral circulatory system lies in tissue, of a specialized nature, the main

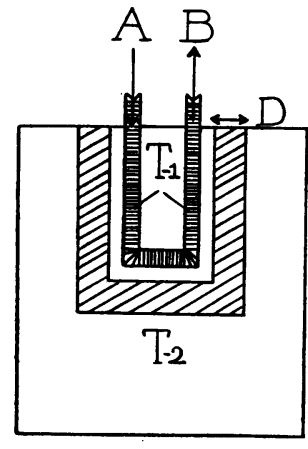

a

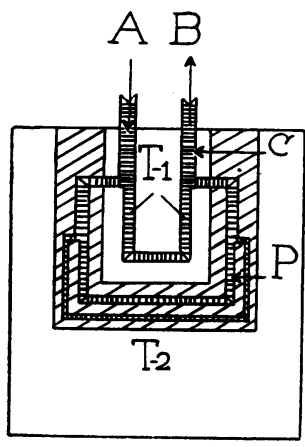

b.

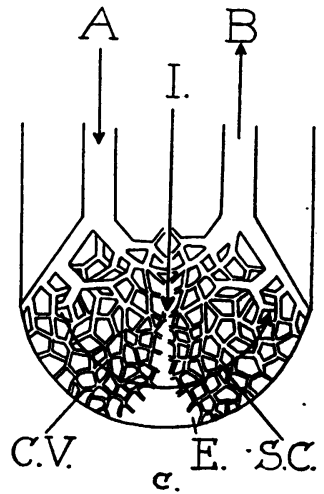

Fic. 1. (a) The principles underlying the transfer of heat from a system of circulating liquid $A B$ at temperature $T_{1}$ through a layer of material of thickness $D$ and conductivity $K$, the temperature gradient being $T_{1}-T_{2} ;(b)$ the conditions when the circulatory system, from the physical standpoint, consists of two portions, a central one $C$ and a peripheral one $P ;(c)$ diagrammatic sketch of circulation of the blood from artery $A$ to vein $B$ through capillary network; $C . V$., capillary venules; $E$., epidermis, and $S . C$. , surface capillaries.

function of which is the regulation of heat and thus is concerned with modifications of blood content and changes in the peripheral vessels. From the physiologic side there is evidence to indicate that moderate variations in one of these two general portions of the circulatory system of an extremity may function independently of the other. Recent investigations on the independent behavior of the skin capillaries when the arterial flow of blood is stopped adds some proof to this assertion (3). 
It is also well known that the heat taken up by the calorimeter can be found from the equation

$$
H=\left(m+m_{0}\right)\left(T_{2}-T_{2}\right)
$$

in which $H$ is the heat in calories developed in the calorimeter, of water equivalent $m_{w}$, containing a mass of water $m$, while $T_{3}-T_{2}$ represents the rise in temperature during a given time $t$.

If, therefore, there are no losses in the calorimeter, or if such losses are determined and added into equation (2), then equations (1) and (2) are identities.

The temperature of the arterial blood in the extremities doubtless varies slightly in different cases. Stewart (8) carefully investigated this matter and says: "We can consider that $36.7^{\circ} \mathrm{C}$. cannot be far from the temperature of the arterial blood in this experiment." In the investigations presented in this paper, $37^{\circ} \mathrm{C}$. has been taken, in general, as a satisfactory temperature, since the variation of a fraction of a degree in the value of the temperature of the arterial blood, cannot affect the conclusions to be drawn.

The increase of temperature of $M$ grams of water ( $m$ of water, and $m_{w}$ the water equivalent) is

$$
\frac{Q}{M}=\frac{H}{\left(m+m_{w}\right)}=K_{\mathbf{2}} \frac{\Delta T}{M} \cdot t
$$

where

$$
\Delta T=37^{\circ}-T^{\bullet}
$$

$T$ being the temperature of the water bath and $37^{\circ}$ that of the source, or

$$
\frac{Q}{M}=K_{2}\left(37^{\circ}-T^{\circ}\right) t
$$

where

$$
K_{2}=\frac{K_{1}}{M}
$$

Therefore, the rate of increase of the temperature of the immersion bath is given by

$$
\frac{d T}{d t}=K_{2}\left(37^{\circ}-T^{\circ}\right)
$$


Integrating

$$
\int \frac{d T}{37-T}=\int K_{2} d t
$$

Hence,

$$
-\log \cdot \theta(37-T)=K_{2} t+C
$$

or

$$
-2.3 \log \cdot{ }_{10}(37-T)=K_{2} t+C
$$

And finally,

$$
-\log \cdot \cdot_{10}(37-T)+K_{3} t=C_{2}
$$

in which

$$
K_{3}=\frac{K \cdot A}{2.3 D \cdot M}
$$

It is to be noted that the term $K_{3}$ includes the conductivity constant $K$, the area $A$, and the thickness $D$.

If then, $T_{1}$ represents the temperature change of the extremity $\Delta T_{1}$ at time $t_{1}$, and $T_{2}$ the temperature change of the extremity $\Delta T_{2}$ at time $t_{2}$, we have

$$
\log \cdot a-\log \cdot T_{1}=K_{8} t_{1}
$$

and

$$
\log \cdot a-\log \cdot T_{2}=K_{8} t_{2}
$$

in which $a$ is taken as $37^{\circ} \mathrm{C}$. in my experiments.

Whence (5),

$$
K_{3}=\frac{1}{\left(t_{1}-t_{2}\right)} \cdot \log \cdot{ }_{10} \frac{T_{2}}{T_{1}}
$$

Equation (8) is, therefore, the fundamental one involved in all of these calorimetric studies, and from a determination of $K_{3}$, the rate of transfer of heat from the extremity immersed in a water bath, both in normal and abnormal subjects, it may be possible to establish conclusions of clinical importance. 
Objections may be raised to the statement that the temperature gradient, that is, $\Delta T$, is at all times equal to $37^{\circ}-T^{\circ}$, in which $37^{\circ} \mathrm{C}$. is taken as the temperature of the arterial blood and $T^{\circ}$ is the temperature of the bath at any specified time, $t$. The assumption of a constant blood temperature of $37^{\circ} \mathrm{C}$. gives, in the data and curves presented in this paper, the minimal rates of heat elimination, and postulates that the temperature of the venous blood leaving the extremity is close to the temperature of the arterial blood. Stewart (8) says, "When a part is immersed for a considerable time in water of a given temperature, much the greater part of the venous blood must have a temperature not very different from that of the bath." If, therefore, we accept Stewart's conclusion, we should take as the temperature of the blood the average of the arterial $\left(x^{\circ}\right)$ and venous, or calorimetric $\left(y^{\circ}\right)$, temperatures, or $\frac{x^{\circ}+y^{\circ}}{2}$. Under these assumptions, therefore,

$$
\Delta T=\frac{x^{\circ}+y^{\circ}}{2}-T^{\circ}
$$

and equation (8) comes out in identically the same form and manner as on the assumption that $\Delta T=37^{\circ} \mathrm{C} .-T^{\circ}$. The initial temperature level only differs in the two assumptions. Such differences in assumptions relative to the temperature of the blood, however, will give different numerical values when the experimental data are substituted in equation (8). But the ratios of the rates of elimination of heat between normal and pathologic conditions will remain the same irrespective of the temperature which is taken to represent that of the blood. For example, the value of $K_{3}$ in a given normal person (curve 5, figs. 3 and 6 ), on the assumption of a blood temperature of $37^{\circ} \mathrm{C}$., is 0.00060 , and the value of $K_{8}$ in a given case of polycythemia (curve 1, figs. 4 and 7 ) is 0.00118 . The ratio of these values is practically $1: 2$. Taking the experimental data for the normal selected (table 1 , curve 5 , figs. 3 and 6 ), and starting at the time $t$, which equals twenty minutes (at which time the so-called "equilibrium" conditions may be said to exist), we find that $x^{\circ}=36.7^{\circ} \mathrm{C}$. and $y^{\circ}=20.7^{\circ} \mathrm{C}$., with an average value of $29.26^{\circ} \mathrm{C}$. The calorimetric temperature is $21.85^{\circ} \mathrm{C}$. at the time $t$, which equals twenty 
minutes. Therefore, at the time, $t=20$ minutes, $\Delta T=29.26^{\circ}$. At the time, $t=80$ minutes, $\Delta T=30.40^{\circ}-24.05^{\circ}$. From these data $K_{3}=0.00112$. In a similar manner it can be shown that in the selected case of polycythemia (curve 1 , figs. 4 and 7) $K_{3}=0.00231$. The ratio of these values is practically $1: 2$. These and other like calculations indicate that the matter of the assumption of the temperature of the blood does not enter into the discussion provided the numerical results obtained are taken as comparative and not absolute values, as is the case in these experiments. The conclusions reached in this paper, therefore, are not affected by any assumptions as to the temperature of the blood, provided it can be stated that the physical and physiologic status of affairs is such that there are no radical changes in the circulatory conditions during the experimental test. We are interested fundamentally in a comparison (or ratio) of rates of elimination of heat in various normal and pathologic conditions, and have no concern with the rate of flow of the blood.

I desire to comment further on the importance of equation (4),

$$
\frac{d T}{d t}=K\left(T_{1}-T_{2}\right)
$$

for this equation states that the rate at which a body loses heat is proportional to the difference between its temperature and that of its surroundings. The rate at which an immersed extremity loses heat is the same as the rate at which heat is being gained by the calorimeter. As time goes on, the temperature gradient between immersed extremity and bath decreases, there is a lessened transfer of heat and as a result the curve representing the relation between temperature and time approaches a temperature the limiting value of which is theoretically the temperature of the arterial blood.

Due regard for the statements made in the preceding paragraph was not taken, I believe, by Stewart in his investigations. The data on Stewart's experiment no. 1, which is presumably typical of his experimental results, is quoted from one of his papers (8).

"At 1:41 p.m. put hands (of M.C.) in bath at $27.0^{\circ}$. Put 3,200 cc. of water in calorimeter $L$ (left hand) and $3,000 \mathrm{cc}$. in $R$ (right hand). Room temperature $18.8^{\circ}$. Mouth temperature $36.8^{\circ}$. Pulse 107. . . . . Volume of right hand in calorimeter $435 \mathrm{cc}$., of left, $410 \mathrm{cc."}$ 
Then follow the experimental data having to do with the rise in the temperature of the calorimeter bath. The increases of temperature with time as shown by Stewart are plotted as curve 1, figure 2, the symbol $(X)$ being for the right hand and $(\bullet)$ for the left one. Stewart's concluding remarks are: "For the first part of the experiment ( 7 minutes) the flow comes out at 12.8 grams blood per $100 \mathrm{cc}$. of hand per minute for the right hand, 13.9 grams for the left. For the second part (the last 7 minutes) 10.29 grams for the right and 11.73 grams for the left."

The blood flow is said to have changed from 12.8 grams to 10.29 grams in twenty-two minutes or a change of $2.5 / 11.6$ (average), which is approximately 20 per cent for the right hand, and for the left hand $2.17 / 12.8$ (average), or about 17 per cent. That is to say, the blood flow is said to have changed about 20 per cent in twenty-two minutes in a bath at an initial temperature of $26.75^{\circ} \mathrm{C}$. and final temperature of $28.78^{\circ} \mathrm{C}$. Such conclusions I believe to be erroneous because the relationship between rise of temperature in the calorimeter with time -of immersion of an extremity, as plotted in curve 1, figure 2 (data being taken from the experiment no. 1 of Stewart, to which reference has been made), is not a linear one. This absence of a linear relationship between the rise of temperature and the time, which is again emphasized by curve 2, figure 2, arises for the simple reason that the temperature gradient has changed from $10.05^{\circ} \mathrm{C}$. (that is $36.8^{\circ}$ to $26.75^{\circ} \mathrm{C}$.) at the beginning of the experiment, to $8^{\circ} \mathrm{C}$. (that is $36.8^{\circ}$ to $28.78^{\circ} \mathrm{C}$.) at the conclusion of the experiment. In these statements, $36.8^{\circ} \mathrm{C}$. is taken from Stewart's data as representative of the temperature of the arterial blood in an extremity. It is apparent that the difference in temperature gradient between the initial and final readings is $2.05^{\circ} \mathrm{C}$. or roughly a change of 22 per cent, as is seen by dividing the temperature difference of $2.05^{\circ}$ by 9 (the average of 10.05 and 8 ). It is possible that these changes in temperature gradient have been incorrectly interpreted by Stewart as changes in blood flow. It is obviously a question of rates of increase of temperature of the immersion bath as given by the equation (4),

$$
\frac{d T}{d t}=K_{2}\left(37^{\circ}-T\right)
$$


and that these increases of temperature are dependent on the rates of elimination of heat from the extremity. In the last analysis I believe that one is justified in saying that calorimetric determinations, per se, give data only on the intake or output of heat and not on the mechanism of the production or elimination of heat.

There is, furthermore, no evidence of any change in the rate of heat elimination and, therefore, presumably no proof of any change in the rate of blood flow, as is shown in curve 3, figure 2, in which $\log . \Delta T$, or log. $\left(36.8^{\circ}-T^{\circ}\right)$ is plotted against $t$, the time. This is very nearly a single straight line with, however, some indication of

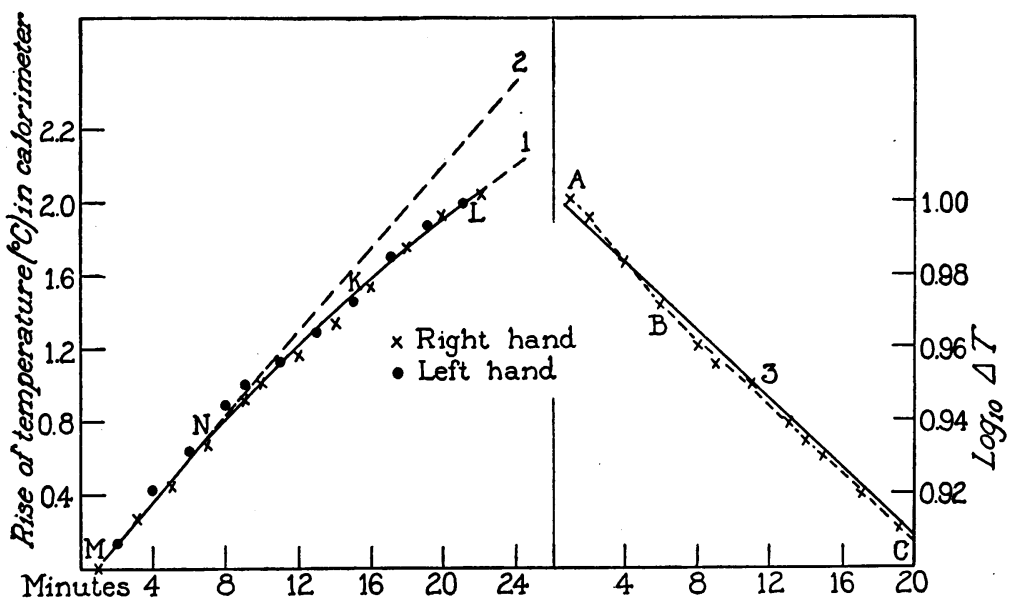

FIG. 2. Curve 1, data plotted from Stewart's paper (8); curve 2, to emphasize the fact that curve 1 is not a straight line, and curve 3 , Stewart's 'data plotted logarithmically against the time $t$.

two portions, marked $A B$ and $B C$, respectively. The slight difference in the slope of the line during the first six minutes of immersion is doubtless due to vasomotor reactions. The curve as a whole, however, conclusively shows that the rate of elimination of heat from an extremity, as determined from calorimetric data given by Stewart, is a constant. There is, therefore, every reason to believe that the rate of blood flow remains constant, provided we include in the definition of the expression "blood flow" the various factors which are known to affect it or to be the equivalent of such flow and which are outlined in the introductory paragraphs of this paper. 


\section{CALORIMETRIC DATA ON THE EXTREMITIES}

Using the apparatus described by Kegerreis, together with accessory means of determining the area of an extremity, Brown has adopted a method of obtaining comparative heat transfers in calories for each square inch of surface. It has been his purpose to simplify the experiments clinically and he has therefore assumed a linear relationship between the rise in temperature in the calorimeter and the time after the break or knee in the curve has been passed. If his procedure is to be accepted as sufficiently exact, it must be justified by a comparison of ratios of the heat capacities of the extremities and the rates of transfer or elimination of heat due to the surface circulation as determined by the use of the logarithmic equation (8),

$$
K_{3}=\frac{1}{t_{1}-t_{2}} \cdot \log \cdot 10 \frac{T_{2}}{T_{1}}
$$

I believe that Brown's results are not to be accepted as specific values of the heat elimination for the particular cases cited or discussed but that, from the clinical standpoint, his simplified method, which assumes a linear relationship between the rise in temperature and the time after the so-called state of equilibrium has been reached, is doubtless sufficiently accurate to permit of some segregation or groupings of cases, and gives ratios, when compared with the values he obtains for normal subjects, which are in excellent agreement with the data and ratios obtained from the methods described anc discussed here. Taking the data given in table 3 , and using ratios obtained from the four methods of analysis of data, I conclude that, in large part, the clinical procedures of Brown furnish data regarding the rate of transfer or elimination of heat to the calorimeter due to the superficial or peripheral circulation as conditioned by skin factors.

The curves of figures 3,4 and 5 represent calorimetric rises in temperature Centigrade when plotted against time in minutes. Figure 3 contains curves showing the increase of temperature of the calorimeter and contents with the time of immersion of an extremity for normal persons; figure 4 for persons clinically grouped as having polycythemia, while the curves of figure 5 contain data on persons having thrombo-angiitis obliterans, or Buerger's disease. These data as graphically presented are taken at random by the writer 
from the clinical experiments of Brown. It is presumed that these and other curves which will be presented will serve as illustrative materials only and that there is not to be read into these discussions any conclusions of clinical significance, for the reason that the data presented for the various clinical subdivisions selected are too meager to warrant their acceptance on any basis other than that of being

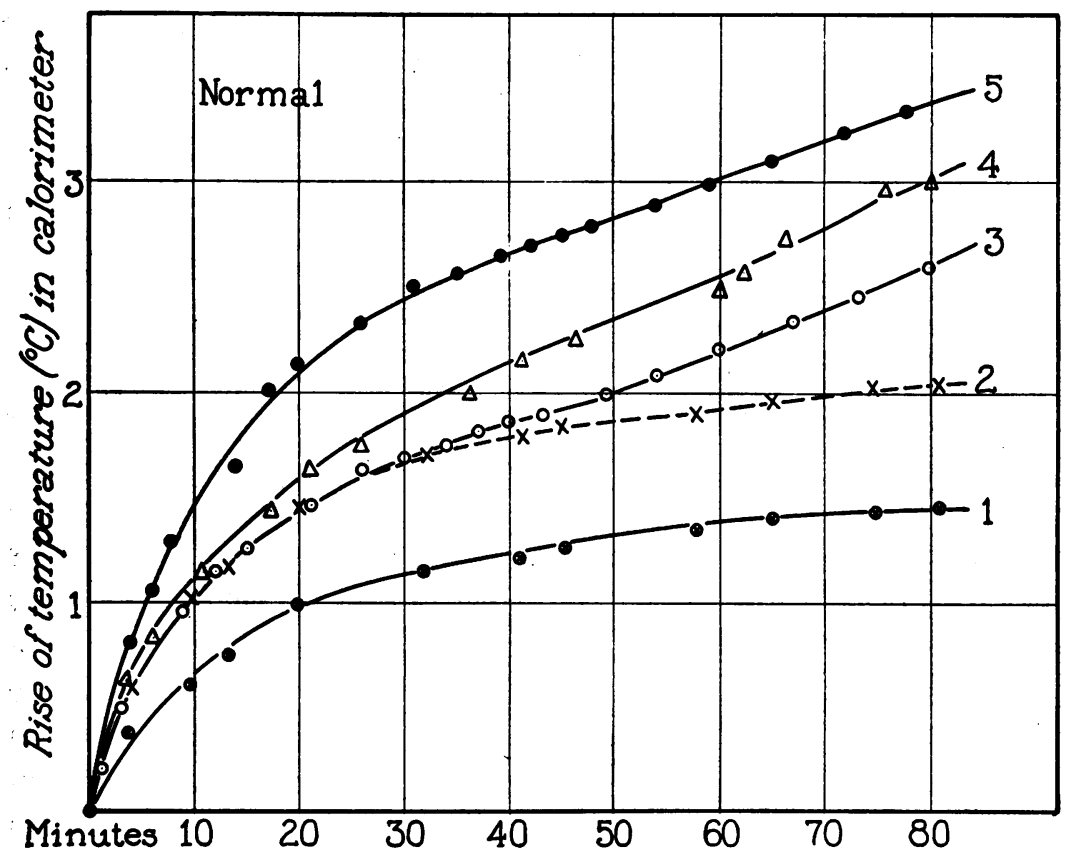

Fig. 3. Curves Showing the ReLattonships between the Rise of Temperature in the Calorimeter and Contents and the TIMe (IN Minutes) OF THE Test

These curves represent data obtained on the same normal individual on different days.

fairly representative of the various groups which are indicated clinically.

In figures 6,7 and 8 are plotted the results of the same experimental tests as are found in figures 3,4 and 5 , in terms of equation (7), that is,

$$
-\log \cdot 10\left(37^{\circ}-T^{\circ}\right)+K_{2} t=C_{2}
$$


in which the $y$ axis is taken as $\log _{10} \Delta T$ and the $x$ axis as the time $(t)$ in minutes. The same order of presentation of clinical classification is made as in figures 3,4 and 5; figure 6 is for the normal, figure 7 for cases of polycythemia, and figure 8 for cases of thrombo-angiitis

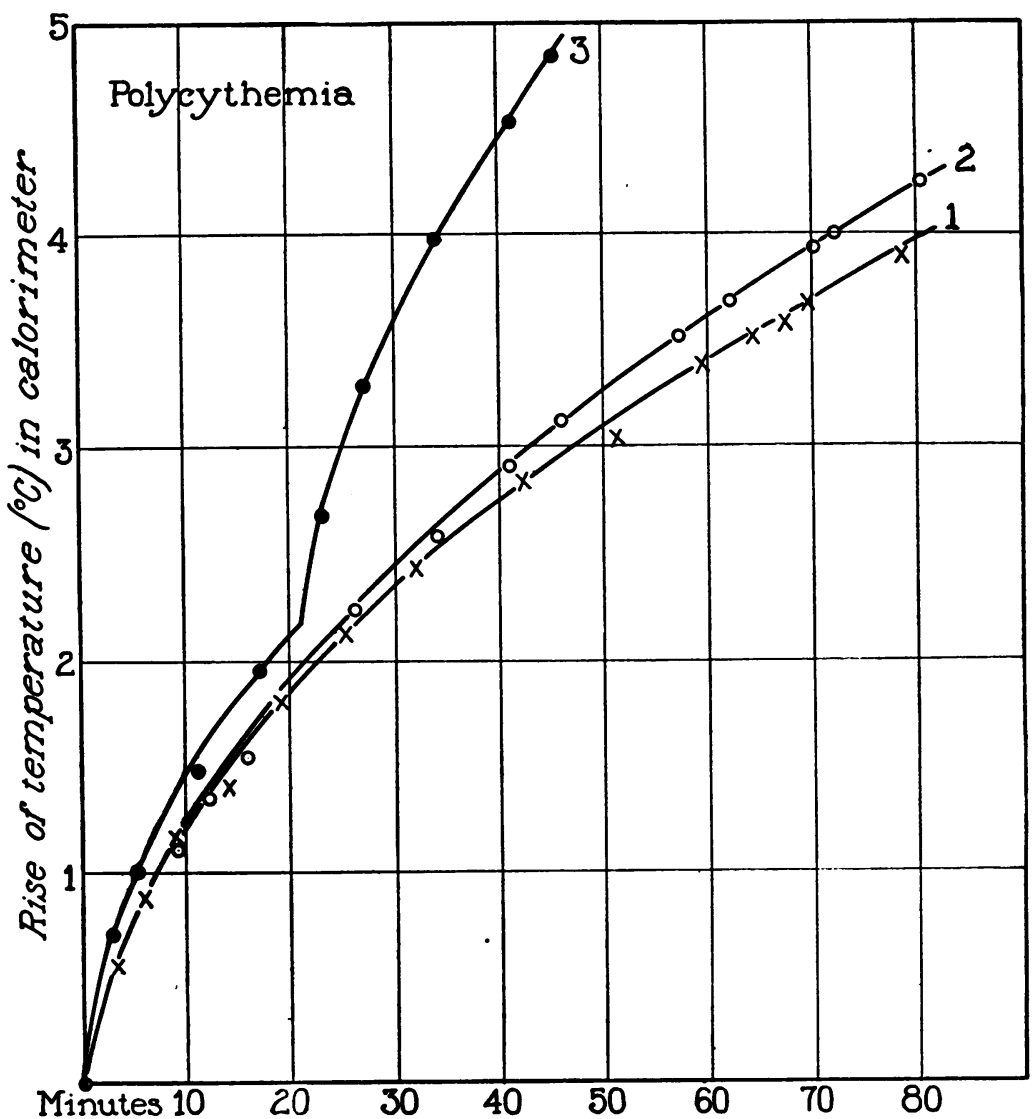

Fig. 4. Curves Showing the Relationships between the Rise of Temperature in the Calorimeter and Contents, and the Time of the Test in 3 CAses of Polycythemia

obliterans. In each instance the curve number appearing in figure 3 is carried over for purposes of identification to the results plotted in figure 6 , and so on.

In table 1 is included a sample set of data for curve 5 , figure 3 , 
as well as the values of $\log _{10} \Delta T$ for which the corresponding curve 5 , figure 6 , is obtained.

It is to be noted that in both the theoretic discussion and in the calculations involving equation (8) as plotted in figures 6,7 and 8 ,

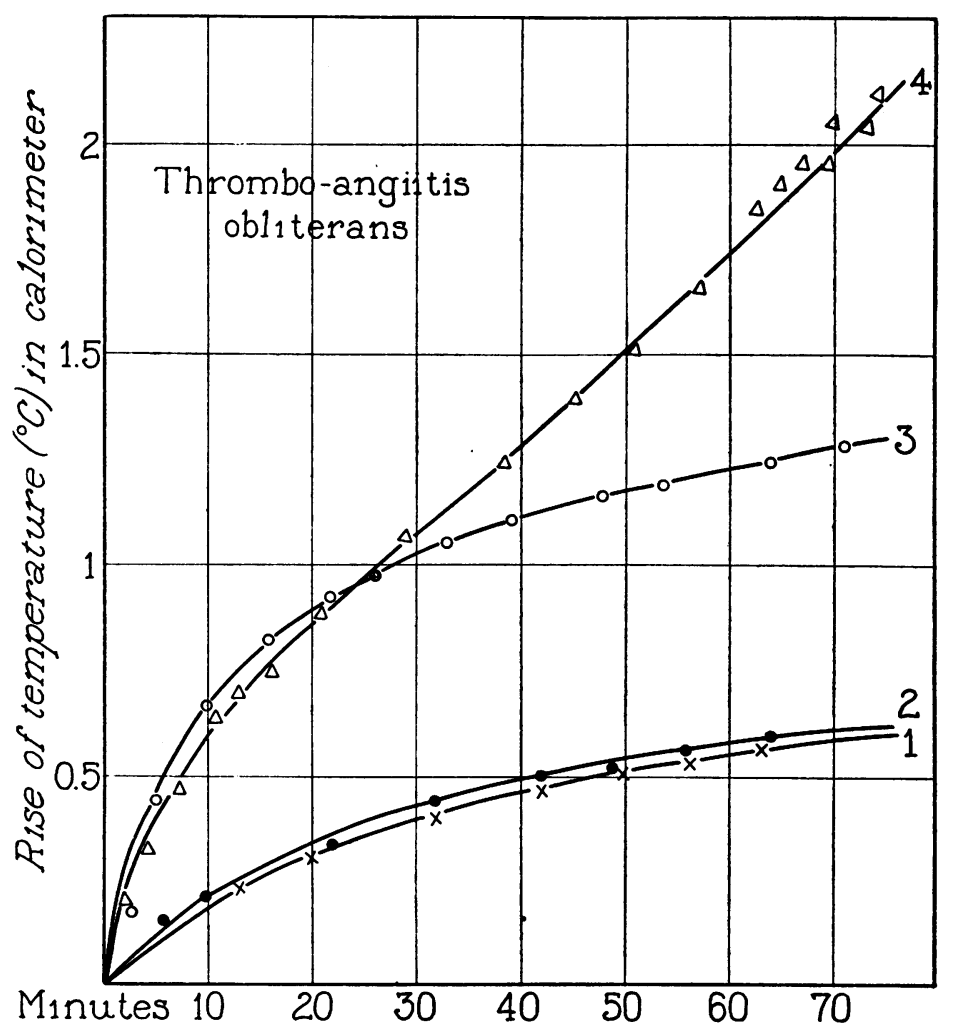

Fig. 5. Curves Showing the Relationships between the Rise of Temperature in the Calormeter and Contents, AND the Tmme of the Tests in 4 Cases of Thrombo-Angitis Obliterans

all reference to the effects of loss of heat by radiation from the calorimeter has been omitted. A series of cooling curves is shown in figure 9. It will be appreciated that, in general, no error comparable to other likely sources of discrepancy and irregularity is introduced by reason of this omission. 
All of the curves plotted in figures 6,7 and 8 , indicating the relationship between $\log _{10} \Delta T$ and $t$ show two portions with decidedly different slopes, therefore indicating two distinct values of the rate of transference or elimination of heat. In the cases of normal subjects, the intersection of these two portions of these curves occurs at the point $B$ (fig. 6) in from fourteen to twenty-two minutes; in

TABLE 1

Data for curve 5, figure 3, and curve 5, figure 6, normal control*

\begin{tabular}{c|c|c|c|c}
\hline Time & Time, minutes & Beckmann reading & $\Delta T=36.7-T$ & Log $\cdot{ }^{\circ} \Delta T$ \\
\cline { 2 - 3 } $10: 21$ & 0 & 1.15 & 15.99 & 1.2038 \\
$10: 26$ & 5 & 2.03 & 15.12 & 1.1796 \\
$10: 27$ & 6 & 2.23 & 14.92 & 1.1738 \\
$10: 29$ & 8 & 2.54 & 14.70 & 1.1673 \\
$10: 35$ & 14 & 2.99 & 14.16 & 1.1511 \\
$10: 38$ & 17 & 3.17 & 13.98 & 1.1455 \\
$10: 41$ & 20 & 3.30 & 13.85 & 1.1414 \\
$10: 47$ & 26 & 3.50 & 13.65 & 1.1351 \\
$10: 52$ & 31 & 3.67 & 13.48 & 1.1297 \\
$10: 56$ & 35 & 3.73 & 13.42 & 1.1274 \\
$11: 00$ & 39 & 3.80 & 13.35 & 1.1255 \\
$11: 03$ & 42 & 3.85 & 13.30 & 1.1239 \\
$11: 06$ & 45 & 3.90 & 13.25 & 1.1222 \\
$11: 09$ & 48 & 3.95 & 13.20 & 1.1206 \\
$11: 15$ & 54 & 4.06 & 13.09 & 1.1169 \\
$11: 20$ & 59 & 4.14 & 13.01 & 1.1143 \\
$11: 26$ & 65 & 4.25 & 12.90 & 1.1106 \\
$11: 33$ & 72 & 4.38 & 12.76 & 1.1059 \\
$11: 39$ & 78 & 4.49 & 12.65 & 1.1021 \\
\hline
\end{tabular}

* August 5, 1924. Systolic blood pressure 110 and diastolic 80; pulse 70. Room temperature $25.4^{\circ} \mathrm{C}$. Main scale of certified Beckmann thermometer set at $19.56^{\circ} \mathrm{C}$. Differential values for preliminary readings were: $1.13^{\circ}$ at $10: 17$ a.m., $1.14^{\circ}$ at $10: 19$ a.m., and $1.15^{\circ}$ at 10:21 a.m. Arterial blood temperature taken as $36.7^{\circ} \mathrm{C}$.

cases of polycythemia, at not less than twenty minutes in any instance (fig. 7), and in conditions of thrombo-angiitis obliterans at from six to ten minutes. Two such separate or distinct portions to each curve would be expected, for during the early period of immersion there is a transfer of heat from the extremity, per se, by reason of the inherent heat or thermal capacity of the foot, plus a transference of heat due to peripheral or surface circulation, while 
secondly, after that which may be spoken of as the steady state, following Stewart's general descriptive notions, has been reached, then the heat which is eliminated and transferred to the calorimeter is due to surface circulatory conditions only $\left(K_{3}=\frac{K A}{2.3 D \cdot M}\right.$. of equation 7$)$. Neither is it to be expected that the transfer of heat due to the inherent heat capacity of the extremity plus that due to the surface

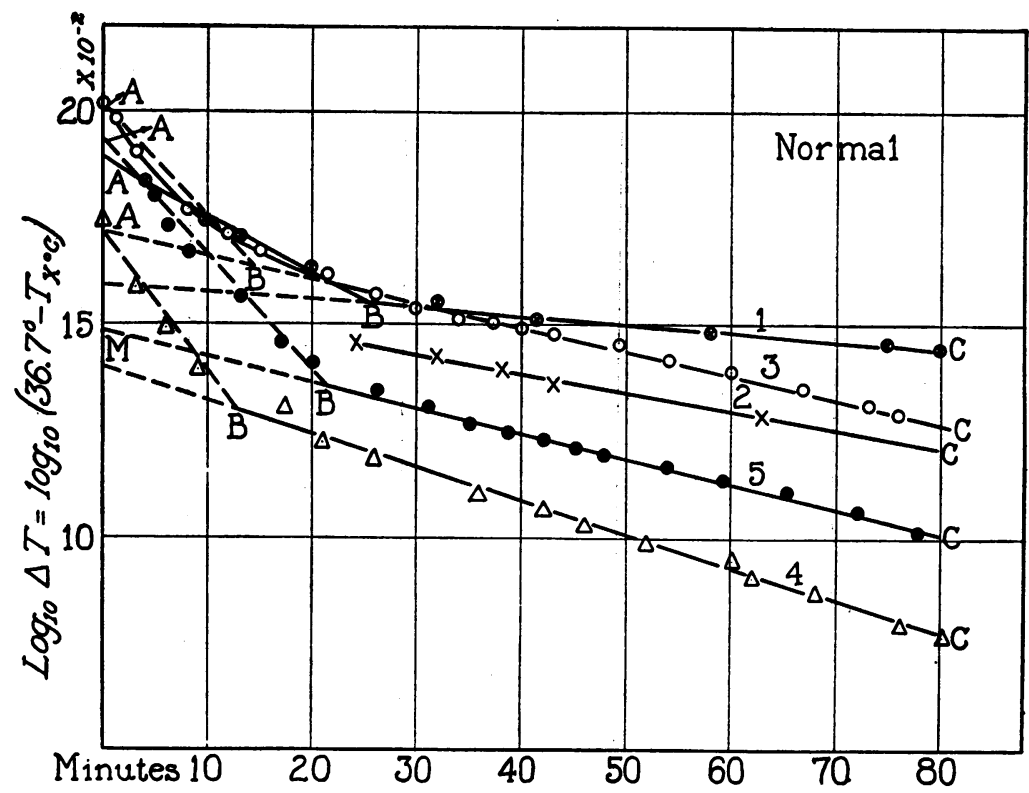

Fig. 6. CuRves Showtng the Relattonships Between $\log _{10} \Delta T$ and the Time $t$ for a Selected Normal Subject

(See figure 3)

circulation, when plotted logarithmically against time, would give a straight line because of: (a) vasomotor reactions; $(b)$ loss of heat from the foot per se, or, as it may be called, depletion of tissue heat or heat capacity of the extremity, and (c) change or decrease in temperature gradient in the superficial tissues of the extremity with time of immersion in the bath. An inspection of the curves shows that the vasomotor reactions are largely completed in from three to six 


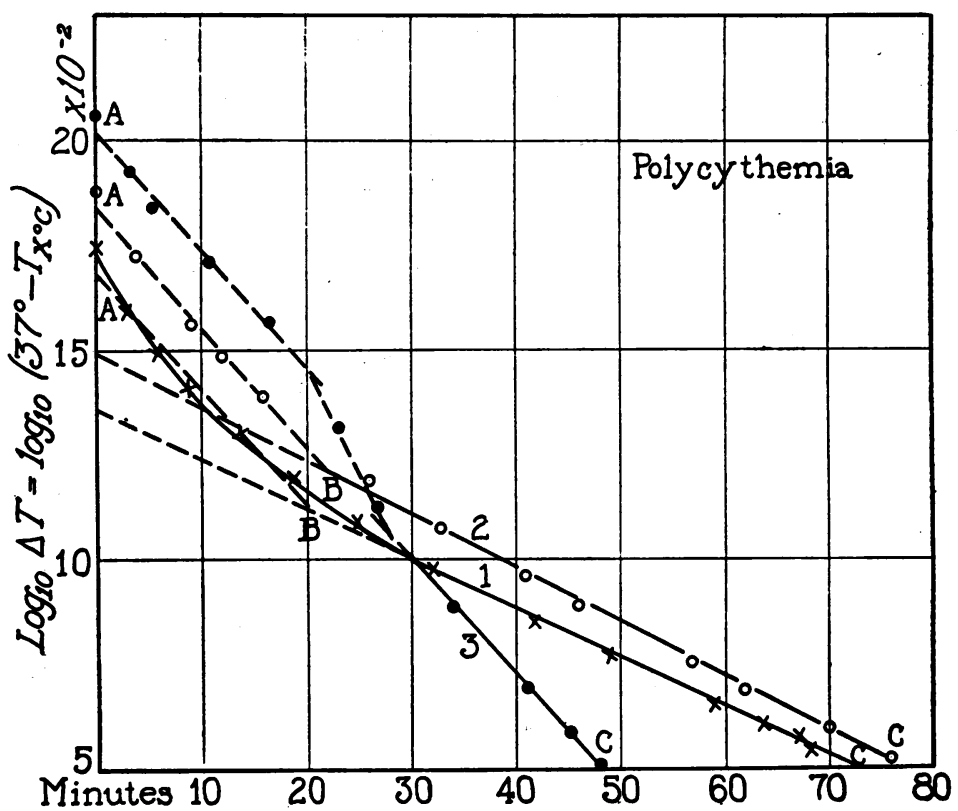

Fig. 7. Curves Showing the Relationships between $\log _{10} \Delta T$ aND the Time $t$ in 3 Cases of Polycythemia

(See figure 4)

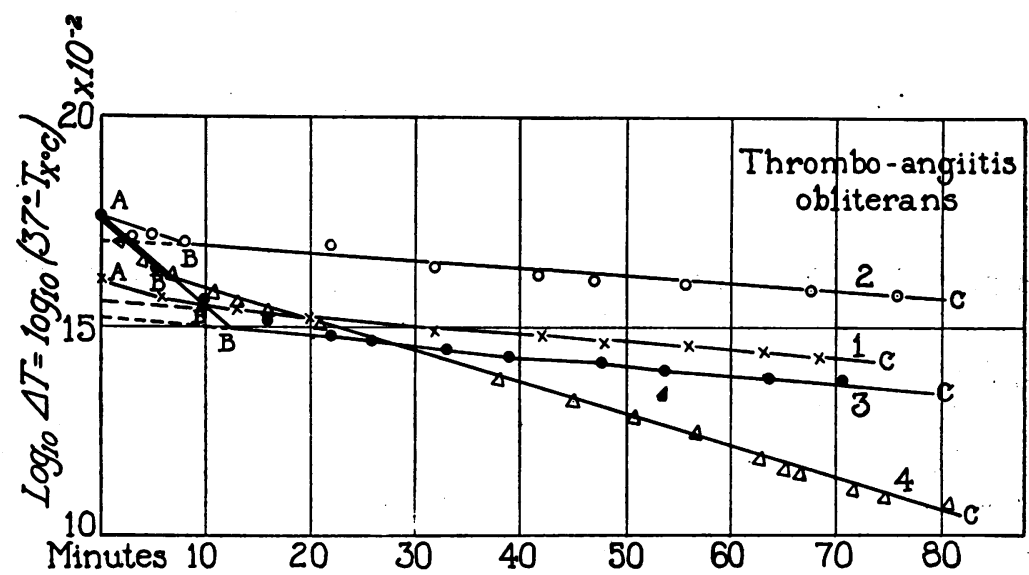

Fig. 8. Curves Showtng the Relationships between log.10 $\Delta T$ AND the Trme $t$ in 4 Cases of Thrombo-Angitts Obliterans

(See figure 5) 
minutes. This is also evidenced in the sample set of data from Stewart and is shown in curve 3 , figure 2. In all the curves of figures 6,7 and 8 , it is found that, from the twenty-minute period on, there is no question that the rate of transfer of heat from the foot due to the superficial or peripheral circulation or distribution of the blood remains constant for each particular case. Hence the relationship

$$
K_{3}=\frac{1}{t_{1}-t_{2}} \cdot \log \cdot 10 \frac{T_{2}}{T_{1}}
$$

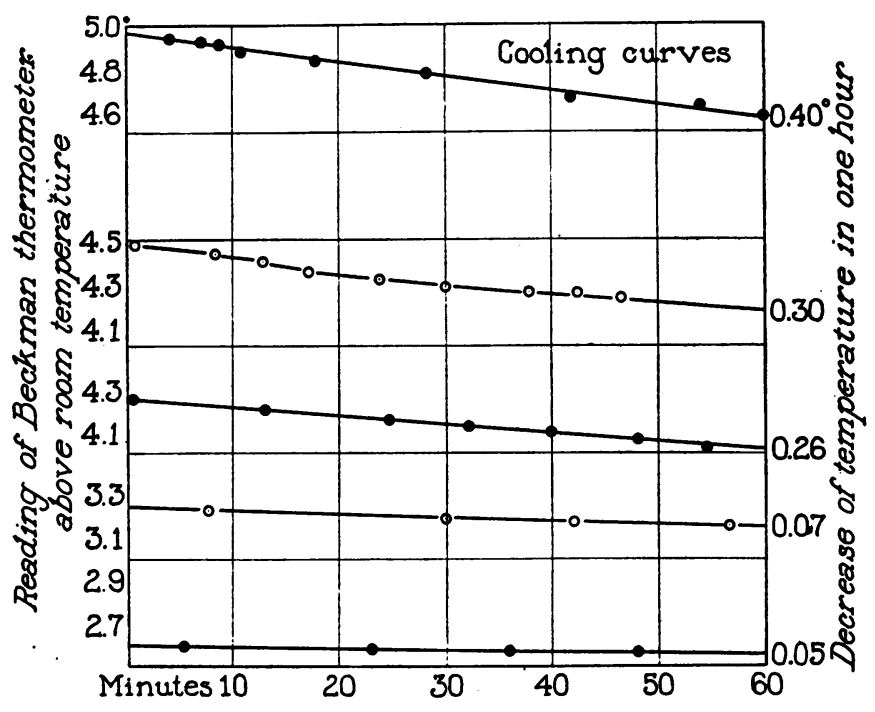

Fig. 9. Calorimetric Cooling Curves

is proved applicable to these investigations. The value of $K_{3}$ (on the assumption that $\Delta T=37^{\circ}-T^{\circ}$ ) for each of the curves of figures 6,7 and 8 is given in table 2 .

It is possible, therefore, to analyze all of the curves of figures 3, 4 and 5 into two portions, namely, the heat delivered to the calorimeter by means of the inherent heat or thermal capacity of the extremity proper, and the heat given up to the calorimeter as a summation effect due to the peripheral blood vessels or surface circulation. Figures 10, 11 and 12 show this analysis graphically. There are three curves in each of these figures; curve 1 represents the heat 
capacity or inherent heat of the superficial portions of the extremity plus the elimination of heat due to the surface circulatory system; curve 2 , the heat eliminated by reason of the surface circulation only, and curve 3 , which is the difference between the readings

TABLE 2

\begin{tabular}{|c|c|c|c|c|c|}
\hline 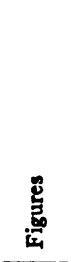 & 总 & $\begin{array}{c}\text { Clinical classification } \\
\text { (Brown's data) }\end{array}$ & 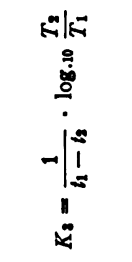 & 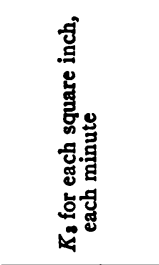 & 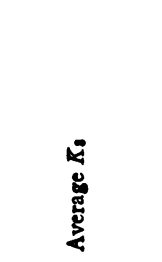 \\
\hline 3,6 & $\begin{array}{l}1 \\
2 \\
3 \\
4 \\
5\end{array}$ & $\begin{array}{l}\text { Normal (same person and dif- } \\
\text { ferent conditions of summer } \\
\text { weather) } \\
\text { (Another person) }\end{array}$ & $\begin{array}{l}0.00020^{*} \\
0.00045 \\
0.00053 \\
0.00073 \\
0.00060 \\
0.00076\end{array}$ & $\begin{array}{l}17 \times 10^{-7} \\
39 \\
46 \\
63 \\
52 \\
62\end{array}$ & $52 \times 10^{-7}$ \\
\hline 4,7 & $\begin{array}{l}1 \\
2 \\
3\end{array}$ & $\begin{array}{l}\text { Polycythemia } \\
\text { Polycythemia } \\
\text { Polycythemia }\end{array}$ & $\begin{array}{l}0.00118 \\
0.00136 \\
0.00300^{*}\end{array}$ & $\begin{array}{l}104 \times 10^{-7} \\
123 \\
232\end{array}$ & $\begin{array}{c}\text { (See Curve } \\
\text { 3, figure } \\
4)\end{array}$ \\
\hline & & $\begin{array}{l}\text { Polycythemia } \\
\text { Polycythemia }\end{array}$ & $\begin{array}{l}000109 \\
0.00127\end{array}$ & $\begin{array}{r}98 \\
113\end{array}$ & $109 \times 10^{-7}$ \\
\hline 5,8 & $\begin{array}{l}1 \\
2 \\
3 \\
4\end{array}$ & $\begin{array}{l}\text { Thrombo-angiitis obliterans } \\
\text { Thrombo-angiitis obliterans } \\
\text { Thrombo-angiitis obliterans } \\
\text { Thrombo-angiitis obliterans } \\
\text { Thrombo-angiitis obliterans } \\
\text { Thrombo-angiitis obliterans }\end{array}$ & $\begin{array}{l}0.00020 \\
0.00020 \\
0.00022 \\
0.00078^{*} \\
\\
0.00019 \\
0.00017\end{array}$ & $\begin{array}{l}23 \times 10^{-7} \\
23 \\
19 \\
78 \\
17 \\
16\end{array}$ & $\begin{array}{l}\text { (Suspected } \\
\text { Buerger's } \\
\text { disease) } \\
19 \times 10^{-7}\end{array}$ \\
\hline
\end{tabular}

* These readings are excluded from the averages.

of curves 1 and 2, the inherent thermal capacity of the extremity. Figure 10 is for an average normal (curve 5, fig. 3), figure 11 for a case of polycythemia (curve 1, fig. 4), and figure 12 for a case of thrombo-angiitis obliterans or Buerger's disease (curve 1, fig. 5). The data 
for curve 2 in each of the figures 10,11 and 12 were obtained by projecting back to intersection with the $y$ axis $\left(y=\log _{10} \Delta T\right)$ the portions $B C$ of the corresponding curves of figures 6,7 and 8 . Since the $B C$ portions of the curves of figures 6,7 and 8 represent the rate of transfer of heat set up by the surface circulatory system only, the values of $\Delta T$ obtained for the initial periods of immersion from the points of the curves under consideration in figures 6,7 and 8 give a measure

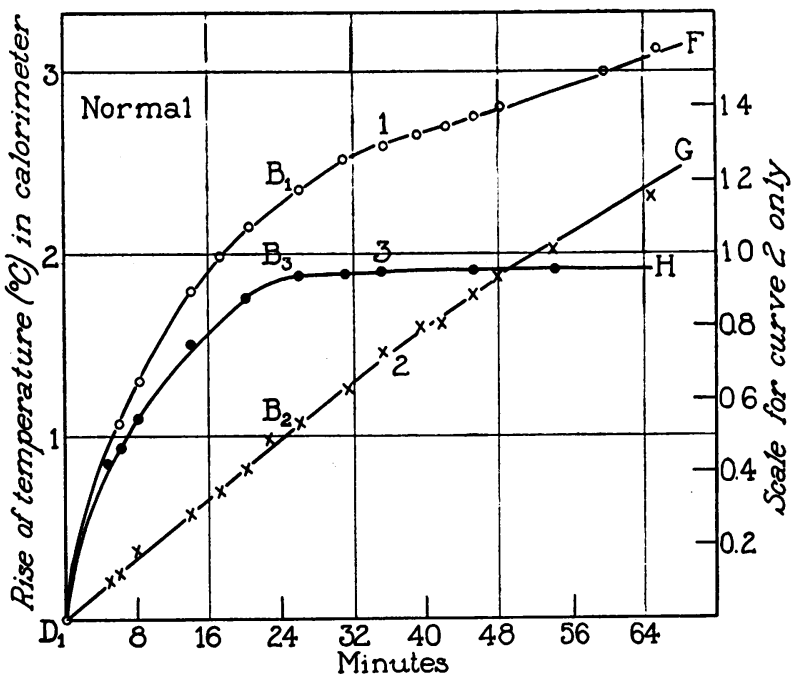

Fig. 10. Curves Shownng the Analysis of the Heat Elmmnated from the Foot of a Normal SUbject

Curve 1, total elimination of heat; curve 2 , heat eliminated by reason of the surface circulation only, and curve 3 , the inherent thermal capacity of the extremity.

of the elimination of heat due to the peripheral or cutaneous circulation only. For instance, curve 2 of figure 10 is obtained by projecting the line $B C$ of curve 5, figure 6 , back to the $y$ axis. By means of the original curve 5 of figure 3 (which is replotted as curve 1 of figure 10), the values of $\Delta T$ for the immersion periods (in minutes) plotted in curve 1, figure 10, can be determined from the projection of the line $B C$ (curve 5, fig: 6). Obviously there is no need to proceed further than the points marked $B$, of figures 6,7 and 8 , since 
the portions $B C$ represent graphically the transfer of heat due to surface circulation only. To amplify these statements $I$ have in figure 10 drawn the complete original curve $D_{1} B_{1} F$ (curve 5, fig. 3 ), the corresponding complete curve $D_{1} B_{2} G$ of heat transfer due to the temperature gradient established by surface circulatory conditions (obtained from curve 5, fig. 6) and the curve $D_{1} B_{3} H$, which is the difference between curves 1 and 2 of figure 10 and which therefore,

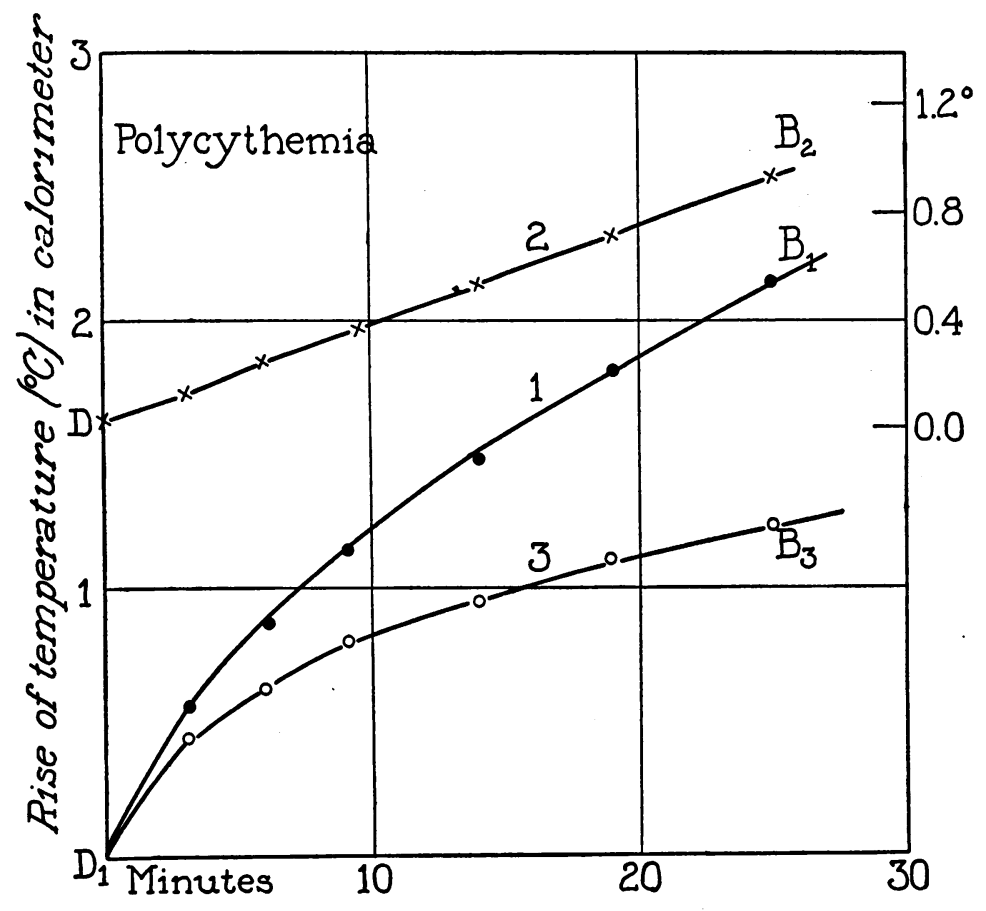

Fig. 11. Same as Figure 10; Cases of Polycythemia

I believe, represents the "temperature rise with time" conditions due to transfer of heat to the calorimeter from the extremity only. It will be noted that the portion $B_{3} H$ of curve 3 , figure 10, is a straight line parallel to the $x$ axis, as it should be.

The data for curve 1 of figure 10 are: mass of water plus the water equivalent of the calorimeter equalled 4,180 grams; $\Delta T$ for the extremity only at the end of twenty-six minutes (point $B_{3}$, curve 3) was $1.88^{\circ}$; the volume displaced by the foot immersed was $1,175 \mathrm{cc}$. 
and the area, as obtained by the Kegerreis method, was 115 square inches. These data show that the heat delivered to the calorimeter, due to the inherent heat or heat capacity of the foot, averages $\mathbf{0 . 2 5 6}$ calorie for each cubic centimeter each minute, or that 2.62 calories for each square inch each minute are delivered on account of this heat capacity. Likewise, considering the same period of time, it can be shown that the peripheral or surface circulation, per se, produced 0.073 calorie for each cubic centimeter each minute, or 0.75 calorie for each square inch each minute. Similar data can be obtained from the curves of figures 11 and 12, for which the accessory data are: volume 1,125 cc., area 118 square inches (fig. 11); and volume $725 \mathrm{cc}$. and area 87 square inches (fig. 12).

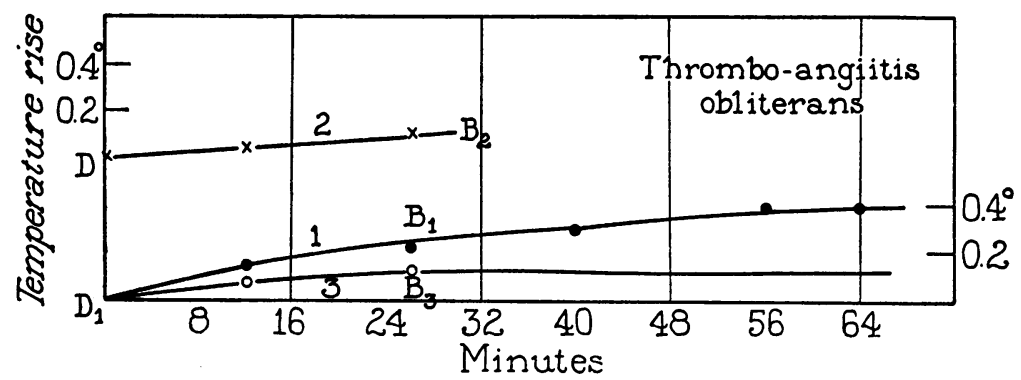

Fig. 12. Same as Figures 10 and 11; Cases of Thrombo-angitis Obliterans

Possibly an easier and just as satisfactory a method, especially in finding ratios between the inherent heats (or thermal capacities) of the extremities of normals and those obtained in cases of disease is to use a planimeter and to find the areas included between the portions $A B$ of the curves of figures 6,7 and 8 and the projections of the lines $B C$ to the points of intersection at the $y$ axis. Such an area is represented as $A B M$ in curve 5, figure 6.

I have included in the data of table 3 , under method 3, the heat capacities of the extremities as determined by obtaining the areas of $(\log . \Delta T) \cdot(t)$. It will be noted from table 3 that the ratio of the average heat capacity of the normal by method 2 to the average normal heat capacity by method 3 is $1.91 / 1.52$, or 1.24 ; and that the ratio of the average heat capacity in polycythemia by method 2 to that by 
method 3 is $2.17 / 1.80$, or 1.21 . These ratios are in excellent agreement. However, in the case of Buerger's disease, this ratio as determined from a comparison of methods 2 and 3 turns out to be $0.55 / 0.11$, or 5 . Possibly no comment is necessary other than that different methods of handling data may give results which are not in themselves necessarily comparable.

TABLE 3

Tabulation of data for curves of figures 3 to 8, obtained by four methods

\begin{tabular}{|c|c|c|c|c|c|c|c|}
\hline \multirow[b]{3}{*}{ Figure } & \multirow[b]{3}{*}{ Curve } & \multirow[b]{3}{*}{ Clinical classification } & \multirow{3}{*}{$\begin{array}{c}\text { Room } \\
\text { tempera- } \\
\text { ture } \\
\text { degrees } \\
\text { C. }\end{array}$} & \multicolumn{4}{|c|}{ Method } \\
\hline & & & & 1 & 2 & 3 & 4 \\
\hline & & & & $\begin{array}{c}K_{3} \text { from } \\
\text { equation } K_{2}= \\
\frac{1}{t_{1}-t_{2}} \cdot \log \cdot 10 \frac{T_{2}}{T_{1}}\end{array}$ & $\begin{array}{c}\text { Heat } \\
\text { capacity, } \\
\text { calories for } \\
\text { each s, fuare } \\
\text { inch, each } \\
\text { minute }\end{array}$ & $\begin{array}{c}\text { Heat } \\
\text { capacity, } \\
\text { arbi rary } \\
\text { units } \\
\text { (ob'ained } \\
\text { with pla- } \\
\text { nimeter) }\end{array}$ & $\begin{array}{l}\text { Ca'ories for } \\
\text { each square } \\
\text { inch, each } \\
\text { minute } \\
\text { (Brown's } \\
\text { clinical } \\
\text { method) }\end{array}$ \\
\hline \multirow[t]{5}{*}{3,6} & 1 & Normal & 18 & $17 \times 10^{-7}$ & 1.52 & 1.75 & \\
\hline & 2 & & 20 & 39 & 1.20 & 0.95 & \\
\hline & 3 & & 21 & 46 & 1.68 & 1.05 & \\
\hline & 4 & & 23 & 63 & 2.12 & 1.92 & 0.97 \\
\hline & 5 & & 25 & 52 & 2.62 & 1.90 & 1.03 \\
\hline \multicolumn{4}{|c|}{ Average. } & $43 \times 10^{-7}$ & 1.91 & 1.52 & 1.00 \\
\hline \multirow[t]{3}{*}{4,7} & 1 & Polycythemia & 19 & $104 \times 10^{-7}$ & 1.90 & 1.70 & \\
\hline & 2 & & 19 & 123 & 2.03 & 1.95 & 1.72 \\
\hline & 3 & & 20 & $232^{*}$ & 2.57 & 1.75 & $3.29^{*}$ \\
\hline \multicolumn{4}{|c|}{ Average $\ldots \ldots \ldots \ldots \ldots \ldots \ldots \ldots \ldots$} & $114 \times 10^{-7}$ & 2.17 & 1.80 & \\
\hline \multirow[t]{4}{*}{5,8} & 1 & Thrombo-angiitis & 19 & $23 \times 10^{-7}$ & 0.49 & 0.10 & 0.25 \\
\hline & 2 & obliterans & 19 & 23 & 0.51 & 0.12 & 0.23 \\
\hline & 3 & & 25 & 20 & 1.56 & 0.90 & 0.30 \\
\hline & 4 & & 18 & $78^{*}$ & 0.66 & 0.10 & \\
\hline \multicolumn{4}{|c|}{ Average $\ldots \ldots \ldots \ldots \ldots \ldots \ldots \ldots$} & $22 \times 10^{-7}$ & 0.55 & 0.11 & 0.26 \\
\hline
\end{tabular}

* These readings are excluded from the averages (see table 2).

\section{DISCUSSION}

The data given in tables 3,4 and 5 enable us to draw some important physiologic conclusions. In the first place, the same person, who was clinically passed as a "normal," was subjected to a series 
of calorimetric tests during the month of August, 1924. In that month the customary changes in summer weather occurred, making it possible to study somewhat the effects of out-of-door or environmental temperature on the data obtained calorimetrically. An inspection of the data in table 3, methods 1 and 2, shows an increased rate of elimination of heat due to surface circulation and also an increased inherent heat capacity with rise of environmental tempera-

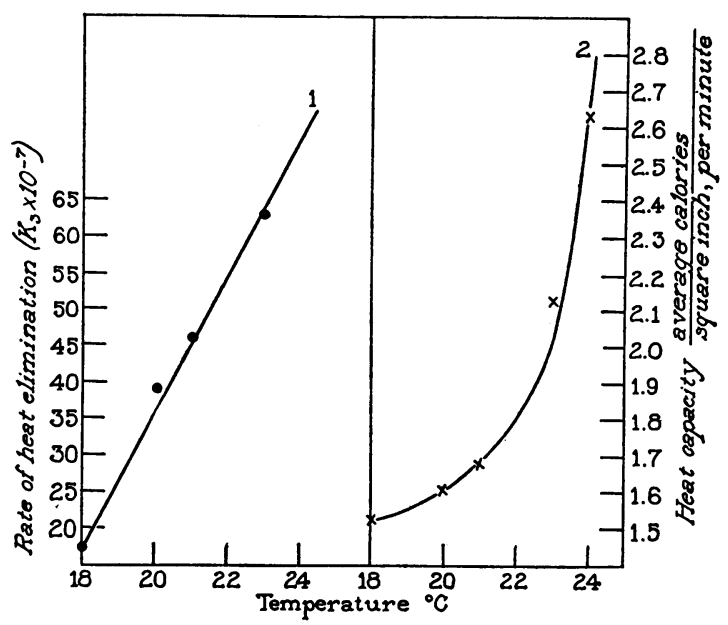

Fig. 13. Curve 1, the relationship between the environmental temperature and the rate of heat elimination $K_{3}$ in the case of a selected normal subject; curve 2, the relationship between the environmental temperature and the inherent heat capacity in the case of the same normal individual.

tures. Figure 13 contains curve 1 , in which the rate of transfer of heat to the calorimeter due to surface circulatory conditions

$$
K_{3}=\frac{1}{t_{1}-t_{2}} \log \cdot 10 \frac{T_{2}}{T_{1}}
$$

is plotted against out-of-door temperatures, and curve 2, in which out-of-door temperatures and inherent heat capacities (average calories for each square inch each minute) are compared, these temperatures being practically those of the room in which the experiments were conducted. These curves are mathematically expressed 
as $y=m x+b$ (curve 1) or the equation of a straight line, and $x^{2}$ $=4$ ay (curve 2) or the equation of a parabola. The values of the constant $a$ for the various experimental values of $x$ and $y$ are shown in table 4.

These and similar curves and data give us a basis for certain deductions which, while they may be but a first approximation to the truth and may need further revision and amplification, are of physiologic importance. In the first place, it appears that, in normal subjects, the rate of transfer or elimination of heat due to surface circulation, that is,

$$
K_{3}=\frac{1}{t_{1}-t_{2}} \cdot \log \cdot 10 \frac{T_{2}}{T_{1}}
$$

TABLE 4

Relationships between environmental temperatures and inherent heat capacities

\begin{tabular}{c|c|c}
\hline$x$ & $y$ & $a$ \\
\hline Temperature, degrees C. & Heat capacity, calories* & From equation $x^{2}=4$ ay \\
\hline 18 & 1.52 & 54 \\
20 & 1.60 & 62 \\
21 & 1.68 & 65 \\
23 & 2.12 & 62 \\
24 & 2.62 & 56 \\
\hline
\end{tabular}

* For each square inch each minute.

is directly proportional to the temperature of the surrounding environment in degrees Centigrade. Secondly, the inherent heat or thermal capacity of the extremity, that is, the ratio of average calories to each square inch, each minute, increases proportionately to the square of the temperature of the environment, expressed in degrees Centigrade, and that there is for each and every normal individual a certain inherent constant $a$, obtained by dividing the square of the temperature in degrees Centigrade by four times the experimentally determined thermal capacity. And again, if curve 1 of figure 13 is projected back to the ordinate, $y=0$, it is shown that in the case of the normal investigated, when the temperature of the surrounding medium reaches from $15^{\circ}$ to $16^{\circ} \mathrm{C}$., the rate of transfer or elimination of heat from the exposed body surface, arising as the result of peripheral circulation, becomes negligibly small. 
The fundamental need of the human body is, without question, to protect the innermost and therefore most vital organs, blood channels and tissues. Hence, as the surface of the body cools off, there is presumably a decrease in the amount of blood carried to the surface, so that ultimately the subcutaneous layer becomes virtually increased in depth and literally serves as a blanket to conserve the heat in the inner portions or, in other words, to lessen the rate of elimination of heat. Roughly speaking, such layers then act as insulating materials, possibly similar to cork, and as a result the effective temperature gradient is markedly affected. The foregoing statements offer some explanation as to why it is that, when at rest for some time and insufficiently clothed, we feel cold and clammy and why we often shiver. For without muscular exercise, which is associated with the increased production of heat, and without adequate means of decreasing the effective cooling surface, peripheral capillary stasis is induced with some constriction of the cutaneous blood vessels. ${ }^{4}$ Shivering is a reflex form of muscular exercise and stimulates the peripheral circulation.

Before passing on, I emphasize that part of the routine in all the the experimental work discussed in this paper, which consisted in keeping the subject without breakfast and at rest for at least onehalf hour before an experimental test, and in making him sufficiently comfortable to insure few, if any, bodily movements, particularly of the extremity immersed in the calorimetric bath. Both of these precautions are quite necessary if useful results are to be obtained.

Furthermore, the curves of figures 3 to 8 inclusive and the data of table 3 show that the average inherent heat capacities (calories eliminated for each square inch each minute) are as follows: normal, 1.91; polycythemia, 2.17, and thrombo-angiitis obliterans, 0.55 . The average values for the rate of heat flow by reason of capillary activity are: normal, $43 \times 10^{-7}$; polycythemia, $114 \times 10^{-7}$, and thromboangiitis obliterans, $22 \times 10^{-7}$ for each square inch each minute. It

\footnotetext{
4 Some recent preliminary experiments by Sheard and Brown, on the effects of insertion of the hand for several minutes into an ice-cooled chamber, have shown microscopically that there is no such capillary constriction and apparently little, if any, dilatation, but that the rate of blood flow in the capillaries is considerably reduced, approximating a condition of stasis.
} 
is not, of course, permissible to attach any undue significance to any average value obtained from the data from a few cases only. But these data substantiate, in a general way, the very conditions which should be expected a priori. For polycythemia is a condition of excess in the number of red corpuscles and in the blood volume. It would therefore follow that the number of active capillaries (and possibly size and rate of blood flow) would be in excess of that found in normal persons, hence giving a greater area of peripheral blood surface, and would therefore enhance the rate of flow of heat as compared with the rate for normal persons. However, the inherent heat capacity of the extremity, in an uncomplicated condition of polycythemia, would be increased but little, the whole mechanism of circulation being regulated to conduct and radiate heat from the surface at a greater rate, under a given temperature environment, than in the normal. This point is further substantiated by various microscopic and photomicroscopic studies of the capillaries in cases of polycythemia made by Brown, from the clinical and medical standpoint, and by my own physical data and experimentation. In such cases, following the reduction of blood volume the number of capillaries, visible and functioning in a given specified area, has been found to be very considerably reduced, although there are but slight, if any, changes in rates of blood flow in the capillaries, or in the calibers or lengths of the visible portions of capillaries.

\section{SUMMARY}

1. Calorimetric methods and data cannot be used to determine the quantity or rate of blood flow.

2. Only quantities $(Q)$ of heat and rates $\left(K_{3}\right)$ of transfer of heat can be determined in such calorimetric investigations, in which a temperature gradient $\left(T_{1}-T_{2}\right)$ exists between the immersed extremity and the calorimetric bath.

3. The equation for heat conductivity, stating that

$$
Q=K\left(T_{1}-T_{2}\right) \frac{A}{D} t
$$

is applicable to calorimetric studies of the extremities. 
4. The rate of increase $\left(K_{3}\right)$ of the temperature of the calorimeter and contents due to the peripheral or surface circulation is given by the expression

$$
K_{3}=\frac{1}{t_{1}-t_{2}} \cdot \log \cdot{ }_{10} \frac{T_{2}}{T_{1}}
$$

5. Analyses of the experimental results made by the use of this equation in which $\log _{10} \Delta T$ is plotted as the ordinate relative to the time $t$ as abscissa, show that there are two distinct portions: (a) that given by the transfer or elimination of heat by virtue of the temperature gradient existing between the foot and the calorimetric bath due to the inherent thermal capacity of the extremity plus the effects due to surface circulation, and (b) that given by the transfer or elimination of heat due solely to circulatory conditions at or near the surface.

6. From a study of a normal person under various conditions of environmental temperature and under the conditions of experimentation stated, there is evidence that: $(a)$ the rate of transfer or elimination of the heat due to the surface or peripheral circulation per $s e$ is approximately very directly proportional to the temperature, in degrees Centrigrade, of the surrounding environment; $(b)$ the inherent thermal capacity of the superficial or surface layers of the extremity increases proportionately to the square of the temperature, in degrees Centigrade, of the surrounding atmosphere or environment, and $(c)$ when the temperature of the surrounding environment falls to approximately $15^{\circ} \mathrm{C}$., the rate of transfer of heat from the exposed surface of a resting body becomes negligibly small as is indicated by the value of the rate of heat elimination due to the existing conditions of surface circulation.

7. A comparison of data on the inherent thermal capacities of extremities in selected normal subjects, three cases of polycythemia and four cases of thrombo-angiitis obliterans (Buerger's disease), shows that there is but little difference in general between that in normal subjects and that in cases of polycythemia, but that there is a marked difference between the values in normal subjects and those obtained in cases of Buerger's disease.

8. A study of the rates of elimination of heat at the surface of an 
extremity, due to conditions of surface circulation, indicates that this rate of heat elimination was found to be from two to five times as great in the cases of polycythemia as in the normal subject under similar environmental temperature, and again, about half as great or less in cases of thrombo-angiitis obliterans (Buerger's disease) as in normal subjects.

9. Tables and discussion of results are given in which the ratios of heat transferred in calories for each square inch of surface of extremity each minute, due to the inherent thermal capacity and the rate of elimination of heat by reason of the peripheral or surface circulation, are compared by various methods.

\section{BIBLIOGRAPHY}

1. Brown, G. E.: Ann. Clin. Med., 1922, i, 69-77. Capillary Observations in Cardiovascular Renal Disease.

2. Brown, G. E., and Giffin, H. Z.: Am. Jour. Med. Sc., 1923, clxvi, 489-502. Studies of Capillaries and Blood Volume in Polycythemia Vera.

3. Cotton, T. F., Slade, J. G., and Lewis, Thomas: Heart, 1915-1917, vi, 227247. Observations on Dermatographism with Special Reference to the Contractile Power of Capillaries.

4. Krogh, August: The Anatomy and Physiology of the Capillaries. New Haven, Yale Univ. Press, 1924, 276 pp.

5. Mellor, J. W.: Higher Mathematics. New York, Longmans, Green and Company, 1919, p. 58.

6. Sheard, Charles: Science, 1924, lx, 409-410. Laboratory Apparatus and Methods. Instantaneous Photomicrography of the Skin Capillaries in the Living Human Body.

7. Sheard, Charles, and Brown, G. E.: Jour. Lab. and Clin. Med., 1924-1925, x, 925-929. A Method for Instantaneous Photomicrography of the Skin Capillaries.

8. Stewart, G. N.: Heart, 1911-1912, iii, 33-88. Studies on the Circulation in Man. I. The Measurement of the Blood Flow in the Hands. II. The Effect of Reflex Vaso-motor Excitation on the Blood Flow in the Hand.

9. Stewart, G. N.: Harvey Lectures, 1912-13, 86-149. Studies on the Circulation in Man. The Blood Flow in the Hands and Feet in Normal and Pathologic Cases.

10. Taylor, N. B.: Jour. Lab. and Clin. Med., 1921-1922, vii, 439-463. The Blood Flow in Man as Estimated by the Calorimetric Method of Stewart.

11. Watson, W.: General Physics. New York, Longmans, Green and Company, 1914 , p. 175. 